\title{
More than a Meeting: Identifying the needs of the community-based seniors' services sector with a research partnership
}

Catherine Tong ( $\nabla$ catherine.tong@uwaterloo.ca )

University of Waterloo https://orcid.org/0000-0002-1214-0591

Joanie Sims-Gould

The University of British Columbia

Sarah Lusina-Furst

The University of British Columbia

Heather McKay

The University of British Columbia

Summit Planning Committee

The University of British Columbia

Research article

Keywords: health services, home and community-based care and services, conference, evaluation, community-based research partnerships

Posted Date: April 6th, 2020

DOI: https://doi.org/10.21203/rs.3.rs-19955/v1

License: (c) (1) This work is licensed under a Creative Commons Attribution 4.0 International License. Read Full License 


\section{Abstract}

Background: Through a weakening of the welfare state, many economically developed countries have seen a decline in publicly funded community programming. Within this context of hollowed-out services for community-dwelling older adults, community-based seniors' service (CBSS) organizations have been increasingly tasked to deliver programs to enable independence, health and social connections for older citizens. In response, CBSS leaders have taken steps to organize as a unified sector and have expanded their partnerships with researchers and universities to enhance and track this work. The primary objective of this study was to capture of the current needs of CBSS leaders in British Columbia, Canada, who attended a seminal event in the CBSS sector's development - the inaugural Summit on Aging (i.e. the Summit). Hosting and evaluating The Summit was a collaborative effort between CBSS organizations and a university-based research team. The secondary objective of this study was to understand the value of hosting the Summit for those who attended.

Methods : We implemented a mixed-method evaluation plan, which included: a pre- $(n=79)$ and post-event online survey $(n=76)$; thematic notes from six breakout sessions, 4 large group sessions, and ethnographic observations from each day of the Summit; and a 6-month post-Summit semi-structured telephone interview $(n=22)$.

Results : Summit delegates identified key opportunities to strengthen the CBSS as a sector, including enhanced collaboration; improved mechanisms that foster connecting and collaborating; and more resources (i.e. funding, trained personnel) to increase their capacity to deliver respond to current and future service demands. Overall, participants found the Summit to be a worthwhile event; it provided a venue to strategize as to how to meet sector needs.

Conclusions : In the context of aging societies and a decline in direct support from the state, we must more meaningfully invest and support the vital work that CBSSs are increasingly providing to older citizens. Here we determine key needs within the CBSS and highlight how an event such as the Summit, can help facilitate collaboration, connections and resources. Our community-based research partnership maximized our collective efforts to robustly capture the changing needs of an evolving sector.

\section{Background \& Objectives}

"Alone we can do so little; together we can do so much." - Helen Keller (American Foundation for the Blind, 2019)

Through neoliberal reforms, a decline in the welfare state, [1] and austerity measures, [2] many economically developed countries have seen a decline in comprehensive, publicly funded support services for older adults. [3] Due to the hollowing-out of centrally supported services, [4] greater demands have been placed on Community-based seniors' service organizations (CBSSs) operated primarily by nongovernmental organizations (NGOs), which are increasingly tasked with delivering health promotion programming [5-7] - a task formally outside the scope, expertise, and capacity of many organizations. 
As Chouinard and Crooks note, [1] "many have looked to the voluntary and non-profit sector as the 'beacon of hope' in terms of [program] delivery support and services to citizens in need of assistance" (p. 173). In British Columbia, Canada, where we conducted our work, many health and social care services for older adults have been downloaded to the non-profit, or 'third' sector.

The third sector is the space that resides "beyond the market, the state, and the household" (p. 1517), [8] and includes the work of NGOs, such as not-for-profit societies, charities, community coalitions, neighbourhood houses. It is worth noting that while the vast majority of CBSSs are offered by NGOs, in some cases, some services are provided by local governments (i.e. community centres) and/or NGO-local government partnerships. [5] For the purposes of this paper, we will collectively refer the organizations that provide CBSSs as residing in the "third sector." The sector provides services in six core areas: nutritional supports; affordable housing; health and wellness; physical activity; education, recreation and creative arts programs; information, referral and advocacy; and transportation. [9]

Globally the third sector is experiencing constrained budgets, greater competition, the impact of austerity measures, and "rising demands for a broader scope of services" (p. 5) [10] - and this is reality applies to the British Columbia's CBSSs. The CBSSs tend to be disconnected from one another for a host of reasons: geography; limited time or opportunity to create networks and collaborate; [11] competition for funding can hinder potential collaborations; $[11,12]$ and a lack of mechanisms for sharing information and best practices with one another. [13] To build on experiences and best practices, maximize the investments of funding, with the aim of preserving the health and wellbeing of older adults, CBSS organizations must find better ways to work together. Other organizations, including government at all levels, publically provided health system organizations, and those within the private sector must also find a way to work together to promote the health and wellbeing of older adults.

CBSS leaders throughout British Columbia crave better connection with other organizations doing similar work. [11] As a response to this need, the inaugural Provincial Summit on Aging (herein referred to as 'the Summit') was designed and held in British Columbia on November 2 nd and 3rd, 2017. The Summit was hosted in partnership with the Raising the Profile Project ( ), United Way of the Lower Mainland, a university-based research team [research team affiliations and universities blinded for review], the City of Surrey, and the British Columbia Recreation and Parks Association (BCRPA). These organizations formed the planning committee and designed the Summit's focus around the learnings from the Raising the Profile Project's community consultations.[9] In an effort to systematically track and evaluate the efforts of their evolving sector, the Summit organizers included members from a university-based team that specializes in community-based gerontological and health research. Drawing on our collective expertise in the non-profit sector, service provision for older adults, and community-based research methods, we forged a community-based research partnership. [14] We forged this partnership in the spirit proposed by Staley and Barron, [15] that our work together was "essentially a conversation where researchers and the public share their knowledge, values and opinions to learn from each other" (p. 8). 
The primary objective of the Summit was to gather CBSS leaders to understand their needs and develop a plan of action. The secondary objective was to determine the value in hosting such an event, relying on our community-university co-designed evaluation. In a cash strapped economic environment, these types of events are expensive and require time and human resources. It was paramount to determine if this type of translational event indeed met the wants and needs of those who travelled to attend the event.

\section{Research Design \& Methods}

To assess the Summit, we worked together to design and implement a mixed-method evaluation approach, which included: a pre- and post-event online survey; thematic notes from breakout sessions, large group sessions, and ethnographic observations; and a 6-month post-event semi-structured telephone interview. We describe the methods for each component in subsections below. We received ethics approval from the University of British Columbia's Behavioural Research Ethics Board for the evaluation of the Summit.

\section{Overview Of The Summit}

The Summit occurred over two full days. Delegates included CBSS leaders (216 invited, 198 participated) and were invited via the networks of the planning committee, and especially connections made through the province-wide community consultations lead by the Raising the Profile Project (RPP). [9] Older adult representatives and members from the university-based team also attended. The Summit proceedings were designed based on learnings of the RPP community consultations, other stakeholder meetings, and the pre-Summit survey. Keynote presentations and panel dialogues addressed demographic trends, a growing need for partnerships and collaboration, emergent opportunities to strengthen the CBSS, and programmatic and service trends. Break out sessions were designed to promote knowledge sharing amongst delegates and the topics of the sessions were on the core services of the CBSS. For detailed proceedings, see http://www.seniorsraisingtheprofile.ca/gatherings/provincial-summit. Another prominent feature of the Summit was the presentation of the first declaration for the CBSS sector (http://www.seniorsraisingtheprofile.ca/wp-content/uploads/2017/10/Summit-Declaration-Final.pdf). Its guiding principles articulate the contributions of the CBSS sector and incorporate concrete commitments to move CBSS work forward.

\section{Pre- And Post-event Online Survey}

Sample. Online survey invitations were sent by email to all registered delegates. For the pre-Summit survey, invitations were sent to 216 people. For the post-Summit surveys, invitations were sent to the 198 people with confirmed attendance. Delegates self-selected to participate. Consent was obtained at the beginning of each survey. 
Data Collection. Pre- and post-Summit surveys were collected via our university's online survey platform, in English. We received 79 responses to the pre-Summit survey, which asked five questions focused on demographics as well as expectations leading into the Summit. We received 76 responses to the postSummit survey, which asked eight questions focused on feedback, connections, and key learnings.

Survey data are presented in the results.

Data Analysis. Pre- and post-Summit surveys text responses were uploaded into NVivo 11 and coded; [16] demographic responses were tabulated in the online survey platform. Main themes and representative quotes were then extracted. Analysis for this portion of the study was conducted by two trained, Masterslevel research assistants.

\section{Thematic Notes And Ethnographic Observations}

Sample. 198 delegates attended the Summit and participated in the breakout and large group sessions. No explicit consent was collected from delegates for notetaking or observation purposes; the Summit facilitators acknowledged that notes and observations were being collected. The research tea, the Active Aging Research Team (AART) consisted of two PhD trained scientists with extensive ( $30+$ and $20+$ years) experience in translational and implementation research, a Masters-level coordinator with more than a decade of research management and event coordination experience, a postdoctoral fellow specialized in qualitative research methods, several graduate-level research assistants, and administrative and communications support staff. The research team worked with Summit leaders from the CBSS to develop the protocols and data collection tools, using an iterative process.

Data Collection. AART staff and graduate students trained in note-taking and ethnographic observations [17] were assigned to specific Summit sessions. We co-created 'observation guides' to assist with the process and ensure consistency. Each breakout session had one note-taker and one ethnographic observer; the larger group sessions had two notetakers and two ethnographic observers.

Data Analysis. Notes were digitally transcribed, and all files were entered into NVivo 11 and coded. One trained research assistant used emergent coding [18] to extract central themes and summarize the notes and observations.

\section{Post Summit Interviews}

The post-Summit interviews occurred approximately six months after the Summit and consisted of the completion of an online form and a semi-structured telephone interview.

Sample. At the Summit, AART members staffed an information table to recruit interview participants and provide information packages containing an invitation letter and a consent form for review. Of the 198 delegates in attendance, 45 indicated interest in participating. Inclusion criteria included attendance at the Summit, 18 years of age or older, and the ability to provide informed consent. Exclusion criteria 
included not being able to read or speak English, being unable to provide informed consent, or did not attend the Summit. Of the 45 individuals who indicated interest and provided contact information, 30 delegates were randomly selected using a randomization tool () and then contacted to confirm their interest and availability in participation. Twenty-three interviews were scheduled and we conducted 22 (one delegate did not return phone calls).

Data Collection. Prior to the interview, participants were sent an email with a link to complete an online form. The form consisted of sixteen questions on demographics, knowledge about Summit follow-up initiatives, and their perceived facilitators and barriers facing the CBSS. Twenty participants completed the survey, with two opting not to complete it due to technical issues. Two trained research assistants conducted the interviews via telephone. The telephone interviews lasted from 10 to 27 minutes and were recorded using an iPhone 4 (Apple Inc., 2010). Respecting the limited time of the CBSS leaders, we intentionally designed the interviews to be comprehensive yet brief. The interview questions aligned with those in the online form and provided an opportunity for participants to expand on their responses. Interview questions are summarized in Table 1 and were co-developed with expertise from the research and community teams. Interviews were professionally transcribed verbatim.

Table 1

Post-Summit Interview Questions.

\section{Post-Summit Interview Guide: Sample Questions}

-What was the most valuable 'thing' about your participation in the Summit? Did it prompt any specific action?

- Did any new partnerships evolve from your participation in the Summit?

If yes, what are your areas of mutual interest (i.e. specific services or issues)?

Have these connections prompted collaborative work?

How have you followed up on the connections (i.e. phone meetings, in-person planning sessions)?

- From your perspective, how adequate are the seniors' services in your community? Please share

some insights on what specific services that are working well and not working well in your

community.

-What is required to build and strengthen CBSSs at the local level?

- What resources do you need to move forward in your work supporting community-based seniors' services?

- How can CBSSs respond to this expectation to become better positioned to serve as health promotion spaces for seniors?

-What role could an organization like yours play in the CBSS sector?

- In your local area, are there local planning tables or communities of practice that focus on seniors' services?

Data Analysis. We de-identified transcripts, and entered both the interview data and text survey responses into NVivo 11 for analysis. Two Masters-level research assistants, both of whom participated in the Summit as note-takers and observers, independently read three transcripts and survey responses to propose a preliminary, emergent coding structure.[18] After reviewing the initial coding structure as a team, the same assistants each coded half of the remaining transcripts independently. Coding was again reviewed by AART, and one research assistant developed a narrative summary of the final themes, with data excerpts, drawing on all transcripts, survey responses and coding nodes. 


\section{Consolidated Analysis}

Upon completion of an initial analysis for each data type, we cross-referenced high-level themes from all data sources $[19,20]$ : the survey responses (both quantitative and qualitative), ethnographic observations and interview transcripts. We utilized framework analysis for our consolidated analysis of all data sources. Framework analysis is adapted to research that has specific questions, a pre-designed sample and a priori issues. [21] The prime concern is to describe and interpret what is happening in a particular setting or context, [22] in our case the CBSS in one Canadian province. In the analysis, data is sifted, charted, and sorted in accordance with key issues and themes using five steps: 1 . familiarize; 2 . identify a thematic framework; 3. index; 4. chart; and 5. map and interpret. [21, 22] As noted, two team members read through the transcripts and notes to get a sense of the data (familiarize). Through a series of team meetings, we developed preliminary thematic framework, consisting of themes and sub-themes, based on key issues and common themes emerging from the transcripts, surveys and notes. Initial codes included: most valuable thing about summit, partnerships and collaboration, build and strengthen CBSS sector, future meetings, sector as a space for health promotion, and opportunities (index). For comparing and contrasting themes within and across the different data sources, we adopted the constant comparison method [23] which allowed us to discover similarities and differences (index). We collated these high-level themes in a coding framework, [24] with data excerpts and definitions (chart), and identified the themes that were representative across each of the evaluation methods (map and interpret). These high-level, representative themes are presented in the results, and were reviewed by both university- and communitybased team members to prior to publication. [28] A preliminary summary of the community-university evaluation was shared with every participant, via a plain-language PDF report. Participants were invited to share their feedback on the report via email or telephone.

\section{Results}

Integrating all data sources and applying an appreciative inquiry view to the data, [26] we distilled concepts that can inform next steps for the CBSS. Given the nature of in-depth interviews, this was the most data-rich source. Survey data for the whole sample is summarized in Table 2, and the richer interview data presented below. Of the 22 individuals who participated in the post-Summit interviews, 16 represented a not-for-profit organizations, two local government, two health services (including regional health authority staff), one private industry and one unspecified. Summit participation was invitational and primarily targeted CBSS leaders. Interviewees included executive directors $(n=8)$, management and administrative staff $(n=8)$, representatives from boards and advisory committees $(n=4)$, and others $(n=$ 2). 
Table 2

Pre-Summit $(n=79)$ \& Post-Summit $(n=76)$ Surveys.

\begin{tabular}{|c|c|}
\hline \multicolumn{2}{|l|}{ Pre-Summit Survey $(n=79)$} \\
\hline Variables & $\mathrm{n}(\%)$ \\
\hline $\begin{array}{l}\text { Type of organization } \\
\text { Not for profit } \\
\text { Local government } \\
\text { Health services (including local health authority staff) } \\
\text { Provincial government } \\
\text { Academic institution } \\
\text { Health professional } \\
\text { Funding agency } \\
\text { Other }\end{array}$ & $\begin{array}{l}55(73.3) \\
13(17.3) \\
5(6.7) \\
5(6.7) \\
5(6.7) \\
3(4.0) \\
1(1.3) \\
12(16.0)\end{array}$ \\
\hline $\begin{array}{l}\text { What do you hope to take away from the Summit? } \\
\text { Seeking partnerships \& collaborations } \\
\text { Gain new knowledge } \\
\text { Meet with old colleagues, deepen established relationships }\end{array}$ & $\begin{array}{l}41(51.8) \\
28(35.5) \\
10(12.7)\end{array}$ \\
\hline \multicolumn{2}{|l|}{ Post-Summit Survey $(n=76)$} \\
\hline $\begin{array}{l}\text { Was the summit valuable to you? } \\
\text { Yes, very valuable } \\
\text { Yes, somewhat valuable } \\
\text { No, not valuable } \\
\text { Not applicable }\end{array}$ & $\begin{array}{l}30(39.5) \\
38(50.0) \\
5(6.6) \\
3(3.9)\end{array}$ \\
\hline $\begin{array}{l}\text { What are the most important next steps for Summit organizers? } \\
\text { Development of a funding strategy } \\
\text { Support for community-level planning and coordination } \\
\text { Launch of an online knowledge sharing platform } \\
\text { Other needs }\end{array}$ & $\begin{array}{l}23(33.3) \\
22(31.9) \\
15(21.8) \\
9(13.0)\end{array}$ \\
\hline t missing data, $n=69$ for this question & \\
\hline
\end{tabular}

\section{Thematic Findings: Sector Needs And Responses}

We identified three high-level themes that can capture the needs of the CBSS, and how we might respond to them: 1.) the CBSS is pursuing collaborations, particularly with the health services, the provincial government, and with other CBSS organizations; 2.) the sector seeks mechanisms to enhance knowledge sharing and connections across CBSS organizations; and, 3.) organizations require the capacity to deliver these essential services, namely sustainable funding. We conclude that the Summit was a worthwhile first step in pursuing these needs.

\section{Need \& Response 1: The Cbss Is Pursuing Collaborations}


Seventy-nine percent of the delegates who completed the post-Summit survey stated that they made connections at the Summit that will support their CBSS work. These collaborations are meant to support their community-based work for older adults. Given the needs of an aging population, much of this work focuses on health.

Collaborations for Health. Delegates recognize that they are increasingly delivering programs and services support health, both in a maintenance and preventive function. As a result, delegates would like to cultivate more formal, reliable collaborations with health care professionals, the local health authorities (British Columbia's publicly provided health system organizations) and the provincial government- and in doing so leverage skills, resources and supports to be more effective in their health promotion programming efforts. The desired collaborations were viewed as difficult to pursue and achieve. At the time of the post-Summit interviews, new collaborations with health system players had yet to develop. Change like this will take time and requires guidance and mandates from those developing senior care and health care policy. One delegate reflected on their role in protecting older adults' health in the current, siloed model:

The opportunities are many. CBSS have the ability to reduce strain on health systems by offering community-based services that improve seniors' health and reduce social isolation. It would help if health services recognized the value of these programs and supported them. There is also great promise in interdisciplinary health teams that include community service providers. (data source: pre-Summit survey)

Delegates are seeking connections with local health authorities for a number of reasons: they are potential source of expertise and funding and the health authorities and CBSS could and should align strategic goals, activities and priorities for the provision of health supports for older adults.

So I, as I said, run a project now that's about health and prevention and recreation and socialization. I think, again, sharing ideas, broader funding applications, creating awareness and we have to partner with the health authorities. The health authorities need to buy into what we're doing. ... Well, I think that the health authorities could come on board. So they could be a partner, whether that's financial support would be great. But they could also come to events and offer support. (data source: post-Summit interview)

Put more bluntly, one survey response wrote "It is great for us to be involved with health promotion prevention work. The challenge and sore spot for me is we are doing health authority work WITHOUT supports from the [health authority] (emphasis theirs)." In spite of some historical tensions between the CBSS organizations and the health authorities, another delegate felt that these two entities should endeavour to work together:

It seems there is a strong history and distaste in the CBSS to work with the health authorities. It surprised me, and without that collaboration, we won't be successful in achieving our ultimate goals. (data source: post-Summit survey) 
The Summit served as the initial response to this identified need. In their post-Summit surveys, the vast majority of respondents (74\%) expressed that they saw meaningful partnerships or collaborative networks forming in the CBSS. Twenty-five percent of respondents stated that substantial new partnerships formed for them from the Summit. Interview data, however, suggests that these were principally partnerships between and within the CBSS, not with the public sector. Largely, respondents stated that the quality of the connections that they made at the Summit were good and that these connections will be the foundation for longer-term partnerships.

\section{Need \& Response 2: The CBSS is actively seeking connections}

In addition to health-focused collaborations, the CBSS organizations also identified a need to better connect with one another. In British Columbia some CBSS organizations have already engaged in longterm efforts to partner, [11] but the Summit was the first ever initiative to formally connect CBSS leaders from across the province. One of the most dominant themes to come out of the Summit was a call for creating an accessible, web-based platform that would allow CBSSs from across the province to share events and programs, developments in the sector, best practices, funding opportunities, etc. A delegate reflected on why such a platform would be helpful:

And I think that's really great for coordinators of the seniors' programs because then they have camaraderie between other people who are providing the same type of programming. And that's not always possible to do on a local level because there aren't other people providing similar programming. (data source: post-Summit interview)

Another delegate recognized that while the CBSS desires a broader funding structure to support their work, developing a web-based platform might be a more feasible first step following the Summit:

While the funding aspect is critical to address, I see the Knowledge Hub [the online platform] as an opportunity to capitalize on some quick wins ... Need to keep the momentum going from such a great Summit. People are solution oriented, and I think ready to take action. (data source: post-Summit survey)

While there was strong support for the platform, delegates also recognized some potential challenges, including not having enough time to use it, insufficient resources to keep the content up-to-date, and concerns about creating an online platform or interface that is truly user-friendly easily searchable. An interviewee noted:

One is simply time. I think the knowledge hub [web-based platform] is going to be a lot like a community of practice I think, an online community of practice. And sometimes the uptake of these things can be challenging when people have limited time, which we do in the sector. So as valuable as a knowledge hub I think will be, it will be one more thing that people have to do or can do on top of their existing workloads. 
So that's- and that's not necessarily something we can change without increasing funding and recognition and support for the sector. (data source: post-Summit interview).

This online portal is not simply an extension of the Summit; beyond connecting leaders within the CBSS, the intent of this portal is to share lessons, co-develop resources, coordinate advocacy work, and, crucially, ensure that different members are not "reinventing the wheel" in their efforts to improve community-based programming for older adults. Post-summit interviews and our team's ongoing collaboration with the CBSS indicates that the portal has been established and is currently in use.

\section{Need 3: The CBSS requires capacity to enact meaningful and sustained change}

All delegates highlighted that in order to execute their vital work for the burgeoning older adult population, they require the capacity to do so. Capacity comes in the form of sustained and predictable funding models; appropriate and accessible spaces; and sufficient human resources, including qualified staff. Delegates emphasized that they require sustained funding, because many of their programs are designed to be low-barrier, which includes being offered for free or low-cost. Many funding streams that support the work of CBSS are competitive and only offered for limited terms. This model is problematic for a number of reasons:

I guess what I'm trying to say is in the past a lot of grants pitted different organizations against each other in the application process. So if we can look at first of all longer term funding for services that requires people to actually work together to get things done. Rather than compete against each other. (data source: post-Summit interview)

We have a recreation/socialization program that is very successful. We are gathering, prepping food, mingling, eating together, and adding intergenerational connectedness with volunteer opportunities. It is working great. Amazing positive feedback from participants, volunteers, service providers, family members, etc. The problem - we have raised funds for year 1 which ends June 30th. We are working on year 2 funding. It is so frustrating to create a program and not know it can be sustained. (data source: post-Summit interview)

Another participant discussed the importance of sustainable and ongoing financial support for programs that are underway. Community-based CBSS programming cannot be solely supported by volunteers:

Our senior service sector is thriving but many of our supports will be eliminated once the funding has finished. Even though we have worked hard at creating sustainable services, the heavy load placed on volunteers, the financial resources available and the cost for which to provide these essential services is beyond what community can do on its own. We currently have a program that literally effects thousands of older adults in our community but once the resources are gone only small areas of the program will be affordable to continue as a legacy. Money is not the only resource at stake; volunteer support, training

Page $11 / 18$ 
and partnerships with larger organizations who see the value of the work need to be engaged. (data source: post-Summit interview)

In the delivery of community-based programming for older adults, CBSSs also require appropriate spaces and qualified staff. One delegate explained:

Appropriate space, you know, just having a space in a building isn't good enough if there's issues with accessibility, where the restroom is, and acoustics and temperature. Those are all, you know, much more important in this age group than it is to another demographic. So the appropriate space is probably the biggest hurdle for us. (data source: post-Summit interview)

I would like for somebody to convince powers-that-be that volunteers for some of these activities are simply not appropriate. That we're putting far too much of an expectation level on volunteers to be there and to commit to regular schedules and commit to levels of responsibility and liability for which they're really not prepared or equipped. So we need the funding to have the people in place. (data source: postSummit interview)

In order to provide preventive and supportive services for older adults, CBSSs are seeking appropriate funding models, and the right spaces and staff in place. Funders and policy makers have not yet responded to these expressed needs. These are the reflections of 198 delegates, leaders of their organizations with decades of experience, and are acutely aware of budget constraints and the needs to their local communities. Their reflections merit consideration.

\section{More than a Meeting: A worthwhile mechanism to identify and action the needs of the sector}

The summit had a number of impacts on participants, reported both in their post-Summit surveys and six months later in their interviews. As outlined above, the Summit and our aligned evaluation efforts allowed for both the identification of needs and led to initial responses. The Summit also raised hopes and energized participants; led to additional work at the community-level; and nearly eighty percent of attendees' organizations signed the declaration affirming their inclusion in the CBSS sector.

Energy and Hope. When asked about their experiences at the Summit, one participant noted that although their perspectives did not change, they realized that the pace of change within the CBSS sector needed to "move faster." Another noted that they were "more sensitive to engaging others, plus the importance of creating regular dialogues with organizations and seniors." Similarly another participant noted:

I was excited by ... a more collaborative movement. Services working in their own silos was the norm and we have been slowing moving away from that - toward a more community development practice. My perspective has shifted to greater hope. (data source: post-Summit interview) 
Impact on Local Work. Participant also discussed taking the discussions, concepts and language of the Summit back to their own local work. For example, one interviewee said:

The most important thing for me was meeting other people from around the province and listening to what was going on in their areas. Following on from that, we are in the process of arranging a workshop in [our local] area to try and develop some of the ideas further. (data source: post-Summit interview)

Another participant was discussing a local seniors' support program, and noted:

I think there'd been some discussion in the past of whether that [program] was valuable, but using the community-based senior services language and talking about what took place at the Summit really solidified the vision for the local group to move forward. (data source: post-Summit interview)

\section{Discussion \& Implications}

Recent research has demonstrated that conferences and summits can be effective tools for supporting individuals, communities and organizations that provide health promotion activities. [27-30] Similar to Fox et al. [27] and Pelletier et al. [30], we too found that thoughtfully enacted and participatory conferences can foster stronger collaborations and professional networking amongst health promotion professionals, researchers and other stakeholders who otherwise do not get an opportunity to regularly meet. Launching and evaluating the Summit required more than a year of consistent planning, consultations and follow-up research, and working collaboratively across the community- and universitysectors. This investment of time and resources produced a province-wide event, fostered strategic linkages between organizations providing similar services to older adults, served as a launch-pad for formally recognizing this groups as a sector, and generated specific and actionable solutions to strengthen this vital work (e.g., an online communication and knowledge sharing portal). In this sense, the Summit was more than a meeting: participants moved beyond the identification of issues and used the Summit to implement change and take action. We have been able to track this action because of our community-university evaluation efforts. These actions included the launch of the online portal, the development of strategic, province-wide partnerships, and the formal declaration of a sector. By the end of the Summit, more than 200 individuals and organizations had signed the declaration.

Through the preliminary community consultations [9] and the Summit evaluation, CBSS participants identified a need to better collaborate with one another. Participant also strongly expressed a desire to better connect with organizations outside of the CBSS, namely the local health authorities. CBSS emphatically note that they are now doing health promotion work, but often without enough collaboration with the publicly funded bodies mandated to promote and protect health provincially and locally. While the CBSS has put in the work to connect and collaborate amongst themselves, a clear and actionable next step will be intentionally and meaningfully connect the third sector with the public sector in their care for older adults. This coincides with health authorities and health care organizations awakening to the realities of an aging population. [31, 32] Both the CBSS and the health care authorities are pursuing the same goal: supporting the health of citizens, including those are the most vulnerable and in-need. [33, 34] 
There is ample potential for mutually beneficial relationships between those two disparate but conceptually aligned service sectors. In previous decades social services and health services were more closely affiliated than they are now; this was the case in British Columbia [5] and other regions and countries. [3] As the aging population continues to rise, now it is more important than ever to re-align these entities.

The work of home and community care, which has recently been downloaded to the CBSS, has historically been unregulated and disparate: the work is decentralized, delivered in private homes and a host of diverse community locations. [36] Workers are unregulated and most do not belong to a professional body, they are often 'lone operators', left to troubleshoot and problem solve without direct supervision and guidance. [36] When this vital but precarious [36] work is downloaded to the third sector, non-profits, these longstanding and well-documented issues are not resolved; at worse they may be exacerbated when this labour and care is delivered by, for example, a peer volunteer or untrained university student. Summit delegates recognized this in their call for qualified staff to deliver health promotion and prevention programing in the CBSS.

Participants also called for increased capacity: in order to do this vital work in as safe and efficient manner, they require sustained, predictable funding, and space to engage in this work. Who and how services are delivered to seniors in the community has dramatically shifted in the last decade, [3] and this has created a context in which CBSSs must coordinate, collaborate and bolster one another's efforts. Participant emphasized, however, that bolstering this sector cannot occur in a funding desert. For example, while the CBSS successfully launched their online portal, even this will require some degree of support to be sustained. Online portals and knowledge sharing have the potential to save time, share resources, and reduce the duplication of efforts. [37] On the part of funders, however, there is a tendency in the not-for-profit sector to assume that once mechanisms are established they magically self-sustain with zero financial support and an over-emphasis on the role of volunteers. $[1,38]$ Through a combination of volunteers, and a dedicated not-for-profit workforce, the CBSS continues its legacy of serving those who are most in need, [34] but it cannot do it alone. Failure to meaningfully support and invest in this sector will be perilous for the organizations themselves, and the older adults that they serve.

\section{Limitations}

We recognize that this is a descriptive analysis conducted at the inception of the Summit and initial efforts to consolidate the CBSS sector. The Summit team, including community and research partners, is committed to following the development of this sector and will continue to track and participate in future forums, so as to better understand the developments over time. We know that evaluating change in community-based organizations is a process that takes years and requires a long-term commitment to research and evaluation; [11] this present analysis will serve as baseline data for future analyses of the sector. We also recognize that this study is limited to one Canadian province, and only represents those individuals who chose and were able to participate it the Summit. 


\section{Conclusion}

In 1835, the French political scientist Alexis de Tocqueville observed that the "science of association is the mother of all science". [39] Nearly two centuries later, organizations are still trying to figure out ways to optimally work together, within and across sectors., and bridging research and community organizations [40] In the context of aging societies and a declining welfare state, we must more meaningfully invest in and support the vital, and increasingly complex, work of the CBSS. Communityuniversity research partnerships are one way we can actively support and track the needs of this sector. Here we offer a general model for assessing efforts in sector development through gatherings (i.e. Summits, conferences) with a robust evaluation approach, and have identified key areas for strengthening this growing and increasingly vital sector.

\section{Abbreviations}

AART: Active Aging Research Team

CBSS: Community-based seniors' services

NGOs: Non-governmental organizations

RPP: Raising the Profile Project

\section{Declarations}

Ethics approval and consent to participate: This study has been reviewed and received clearance from the University of British Columbia's Behavioural Research Ethics Board (H17-02661). All participants provided verbal and written informed consent prior to participating in the research study.

Consent for publication: Not applicable.

Availability of data and materials: Data used in this analysis can be made available, upon reasonable request, by contacting the corresponding author, Dr. Joanie Sims-Gould (email: simsg@mail.ubc.ca).

Competing interests: The authors declare that they have no competing interests.

Funding: This study was funded by a Grant-in-Aid from the BC Ministry of Health as well as a Canadian Institutes of Health Research project grant [grant number PJT-153248]. Dr. Sims-Gould is supported by a New Investigator award from the Canadian Institutes of Health Research and a Scholar award from the Michael Smith Foundation for Health Research.

Authors contributions: JSG, SF, HM and the Summit Planning team conceived of the study and codeveloped the protocols and data collection tools; JSG and SF led data collection and initial analyses; CT 
\& JSG finalized the analysis and wrote the manuscript; all authors reviewed the manuscript prior to publication, including all members of the Summit Planning team.

Acknowledgements: We extend sincere thanks to our study participants for generously sharing their experiences and time. Thank you to research assistants Kaitlin Hong-Tai and Neville Li who assisted with data collection and study coordination. Thank you to the 2017 Summit on Aging Coordinating Committee, including Marcy Cohen, Co-Lead for Raising the Profile Project; United Way of the Lower Mainland; Active Aging Research Team (AART) at the Centre for Hip Health and Mobility (CHHM); City of Surrey; the British Columbia Recreation and Parks Association (BCRPA); and the University of British Columbia.

\section{References}

1. Chouinard V, Crooks VA. Negotiating neoliberal environments in British Columbia and Ontario, Canada: Restructuring of state-voluntary sector relations and disability organizations' struggles to survive. Environment and Planning C: Government and Policy. 2008 Feb;26(1):173-90.

2. Hayes LJ, Moore S. Care in a time of austerity: The electronic monitoring of homecare workers' time. Gender, Work \& Organization. 2017 Jul;24(4):329-44.

3. Lloyd L, Tanner D, Milne A, Ray M, Richards S, Sullivan MP, Beech C, Phillips J. Look after yourself: active ageing, individual responsibility and the decline of social work with older people in the UK. European Journal of Social Work. 2014 May 27;17(3):322-35.

4. Cohen M, McLaren A, Sharman Z, Murray S, Hughes M, Ostry A. From support to isolation: the high cost of BC's declining home support services [Internet]. Canadian Centre for Policy Alternatives; 2006 [cited 2020 March 20]. Available from:

https://www.policyalternatives.ca/publications/reports/support-isolation

5. Kadowaki L, Cohen M. Raising the profile of the community-based seniors' services sector in B.C.: a review of the literature [Internet]. Raising the Profile Project; 2017[cited 2020 March 20]. Available from: http://www.seniorsraisingtheprofile.ca/wp-content/uploads/2017/06/RPP-LiteratureReview.pdf

6. Pardasani MP. Senior centers: Focal points of community-based services for the elderly. Activities, Adaptation \& Aging. 2004 Oct 27;28(4):27-44.

7. Casteel $C$, Nocera $M$, Runyan $\mathrm{CW}$. Health promotion and physical activity programs in senior centers. Activities, Adaptation \& Aging. 2013 Jul 1;37(3):213-23.

8. Salamon LM, Sokolowski SW. Beyond nonprofits: Re-conceptualizing the third sector. VOLUNTAS: International Journal of Voluntary and Nonprofit Organizations. 2016 Aug 1;27(4):1515-45.

9. Raising the Profile Project. What are Community-based Seniors' Services? 2019 [Internet]. Raising the Profile Project; 2019 [cited 2020 January 17]. Available from:

http://www.seniorsraisingtheprofile.ca/about-the-sector/defining-the-sector/ 
10. Smith SR, Grønbjerg KA. Introduction to Special Issue of NVSQ: Nonprofits and Public Policy. 2018 47(S)L5-10.

11. Tong CE, Franke T, Larcombe K, Sims Gould J. Fostering inter-agency collaboration for the delivery of community-based services for older adults. British Journal of Social Work. 2018 Mar 1;48(2):390411.

12. Bunger AC. Administrative coordination in nonprofit human service delivery networks: The role of competition and trust. Nonprofit and voluntary sector quarterly. 2013 Dec;42(6):1155-75.

13. Weiss ES, Taber SK, Breslau ES, Lillie SE, Li Y. The role of leadership and management in six southern public health partnerships: a study of member involvement and satisfaction. Health education \& behavior. 2010 Oct;37(5):737-52.

14. Minkler M. Community-based research partnerships: challenges and opportunities. Journal of urban health. 2005 Jun 1;82(2):ii3-12.

15. Staley K, Barron D. Learning as an outcome of involvement in research: what are the implications for practice, reporting and evaluation?. Research involvement and engagement. 2019 Dec;5(1):14.

16. NVivo 11 [Software]. QSR International. Available from: https://www.qsrinternational.com/nvivoqualitative-data-analysis-software/home

17. Roper JM, Shapira J. Ethnography in nursing research. Sage; 2000.

18. Bradley EH, Curry LA, Devers KJ. Qualitative data analysis for health services research: developing taxonomy, themes, and theory. Health services research. 2007 Aug;42(4):1758-72.

19. Caracelli VJ, Greene JC. Data analysis strategies for mixed-method evaluation designs. Educational evaluation and policy analysis. 1993 Jun;15(2):195-207.

20. Caracelli VJ, Greene JC. Crafting mixed-method evaluation designs. New directions for evaluation. 1997 Jun;1997(74):19-32.

21. Srivastava A, Thomson SB. Framework analysis: a qualitative methodology for applied policy research. Journal of administration \& governance. 2009;4(2):1-8.

22. Ritchie J, Spencer L. Qualitative data analysis for applied policy research. In Analyzing qualitative data 2002 Sep 9 (pp. 187-208). Routledge.

23. Thorne S. Data analysis in qualitative research. Evidence-based nursing. $2000 \mathrm{Jul}$ 1;3(3):68-70.

24. Smith J, Firth J. Qualitative data analysis: the framework approach. Nurse researcher. 2011;18(2):5262.

25. Cashman SB, Adeky S, Allen III AJ, Corburn J, Israel BA, Montaño J, Rafelito A, Rhodes SD, Swanston $\mathrm{S}$, Wallerstein N, Eng E. The power and the promise: working with communities to analyze data, interpret findings, and get to outcomes. American journal of public health. 2008 Aug;98(8):1407-17.

26. Cooperrider DL, Whitney DK, Stavros JM. Appreciative inquiry handbook. Berrett-Koehler Publishers; 2003.

27. Fox A, Gillis D, Anderson B, Lordly D. Stronger together: use of storytelling at a dietetics conference to promote professional collaboration. Canadian Journal of Dietetic Practice and Research. 2016 Oct 
25;78(1):32-6.

28. Magnus E, Knudtsen MS, Wist G, Weiss D, Lillefjell M. The search conference as a method in planning community health promotion actions. Journal of public health research. 2016 Aug 19;5(2).

29. Mendel P, Ngo VK, Dixon E, Stockdale S, Jones F, Chung B, Jones A, Masongsong Z, Khodyakov D. Partnered Evaluation of a Community Engagement Intervention: Use of a "Kickoff" Conference in a Randomized Trial for Depression Care Improvement in Underserved Communities. Ethnicity \& disease. 2011;21(3 0 1):S1.

30. Pelletier C, Pousette A, Fox G, Keahey R, Ward K, Faulkner G, Rasali D, Allison S. Move the north: evaluation of a regional stakeholder engagement initiative to support the development of a community-partnered physical activity research agenda. Research Involvement and Engagement. 2019 Dec 1;5(1):37.

31. Stolee P. South west local health integration network dementia strategy: Whole person, whole Journal. Waterloo, ON: Geriatric Health Systems Research Group; 2015.

32. Stolee P. Informing the south west frail senior strategy. Waterloo, ON: Geriatric Health Systems Research Group; 2018.

33. British Columbia Ministry of Health. Ministry of health: service plan 2019/20-2021-/22 [Internet]. Ministry of Health; 2019 [cited December 17 2019]. Available from: https://www.bcbudget.gov.bc.ca/2019/sp/pdf/ministry/hlth.pdf

34. Raising the Profile Project. Finding and recommendations from the community consultations [Internet]. Raising the Profile Project; 2018 [cited December 17, 2019]. Available from: http://www.seniorsraisingtheprofile.ca/wp-content/uploads/2017/08/RPP-Findings-andRecommendations-from-the-Community-Consultations.pdf

35. Boris E, Klein J. Organizing home care: low-waged workers in the welfare state. Politics \& Society. 2006 Mar;34(1):81-108.

36. Denton M, Zeytinoglu IU, Davies S, Lian J. Job stress and job dissatisfaction of home care workers in the context of health care restructuring. International Journal of Health Services. 2002 Apr;32(2):32757.

37. Quinn E, Huckel-Schneider C, Campbell D, Seale H, Milat AJ. How can knowledge exchange portals assist in knowledge management for evidence-informed decision making in public health?. BMC public health. 2014 Dec 1;14(1):443.

38. Hanlon N, Rosenberg M, Clasby R. Offloading social care responsibilities: recent experiences of local voluntary organisations in a remote urban centre in British Columbia, Canada. Health \& social care in the community. 2007 Jul;15(4):343-51.

39. Tocqueville AD. Democracy in America (A. Goldhammer, Trans.). The Library of America. 2004.

40. Almog-Bar M, Schmid H. Cross-sector partnerships in human services: Insights and organizational dilemmas. Nonprofit and Voluntary Sector Quarterly. 2018 Aug;47(4_suppl):119S-38S. 